\title{
Fray Antón de Montesinos: su narrativa y los derechos de los pueblos indígenas en las constituciones de Nuestra América*
}

\author{
Luis Alfonso Fajardo Sánchez ${ }^{* *}$
}

\begin{abstract}
Recibido: 6 de septiembre de 2012
Evaluado: 11 de noviembre de 2012

Aceptado: 14 de febrero de 2013
\end{abstract}

\section{RESUMEN}

El presente ensayo hace un seguimiento al impacto del sermón Yo soy una voz que clama en el desierto, de fray Antón de Monstesinos, que reflejaba el pensamiento de la pequeña comunidad dominicana asentada en la isla La Española. El trabajo se desarrolla partiendo del contexto histórico en que el sermón fue declarado y que, según los expertos, coincide con el nacimiento de los derechos humanos en Nuestra América y las Leyes Nuevas de Indias, en las que por primera vez la Corona española censura y castiga el maltrato, la muerte y la esclavitud de los indígenas. Se procede a mostrar cómo estos ideales de libertad han sido igualmente desarrollados por las universidades y conventos de América, en el seno de las Naciones Unidas y la Declaración Universal de los Derechos de los Pueblos Indígenas, a la vez que se han concretado como producto del neoconstitucionalismo por los ordenamientos latinoamericanos, como en las constituciones de Colombia, Ecuador y Bolivia. Este artículo muestra cómo la denuncia del fraile debe hacerse extensiva a todos los seres humanos que sufren violencia, hambre, esclavitud, tortura y muerte, es decir, a todos aquellos que sufren violación de los derechos humanos.

Palabras clave: Montesinos, leyes de Indias, derechos de pueblos indígenas, libertad, neoconstitucionalismo, constituciones de América, derecho a la historia.

* Articulo de reflexión presentado para optar al título de posdoctor en Narrativa y Ciencia, convenio Universidad Santo Tomás y Universidad de Córdoba, Argentina.

** Abogado. Licenciado en Ciencias Sociales. Especialista en Derechos Humanos. Magíster en Teorías Criticas del Derecho. Doctor en Derecho. Doctor en Sociología y Ciencias Políticas. Codirector de la línea de investigación de Derechos Humanos y Derecho Internacional Humanitario de la Maestría en Derecho de la Universidad Sergio Arboleda. Miembro del Grupo de Investigación de Las Casas de la Facultad de Derecho de la Universidad Sergio Arboleda. Correo electrónico: Alfonso.fajardo@usa.edu.co 


\section{Fray Antón de Montesinos: his narrative and the indigenous peoples' rights in the Constitutions of our America}

\begin{abstract}
This essay makes a follow-up to the sermon I am a voice crying in the wilderness by Fray Anton de Montesinos, that reflected the thinking of the small Dominican community settled on the island La Española. The work is developed based on the historical context in which the sermon was declared and, according to experts, it coincides with the birth of human rights in our America and the New Laws of the Indies, in which, for the first time, the Spanish Crown censored and punished abuse, death and enslavement of the Indians. We proceed to show how these ideals of freedom have also been developed by universities and convents in America, within the United Nations and the Universal Declaration of the Rights of Indigenous Peoples, which in turn have resulted as a product of the neoconstitutionalism by the Latin American legislation, like in the Constitutions of Colombia, Ecuador and Bolivia. This article shows how the friar's complaint should be extended to all human beings who suffer from violence, famine, enslavement, torture and death, that is, to all those who suffer from human rights violation.
\end{abstract}

Keywords: Montesinos, Indian law, indigenous rights, freedom, neoconstitutionalism, American Constitutions, the right to the history.
Recibido: 6 de septiembre de 2012

Evaluado: 11 de noviembre de 2012

Aceptado: 14 de febrero de 2013 


\section{Frey Anton de Montesinos: sua narrativa e os direitos dos povos indígenas nas constituições da Nossa América}

Recibido: 6 de septiembre de 2012

Evaluado: 11 de noviembre de 2012

Aceptado: 14 de febrero de 2013

\section{RESUMO}

Este ensaio faz uma fiação para o sermão Eu sou a voz que clama no deserto, de Frey Anton de Montesinos, que refletia o pensamento da pequena comunidade dominicana estabelecida na ilha La Española. O trabalho é desenvolvido a partir do contexto histórico em que o sermão foi declarado e que, de acordo com especialistas, coincide com o nascimento dos direitos humanos em Nossa América e as Leis Novas de Índias, nas que pela primeira vez a Coroa espanhola censora e pune o abuso, a morte e a escravização dos indígenas. Prossegue-se a mostrar como estes ideais de liberdade tem sido igualmente desenvolvidos pelas universidades e conventos de América, no seio das Nações Unidas e a Declaração Universal dos Direitos dos Povos Indígenas, ao tempo em que tem-se concretizado como produto do neoconstitucionalismo pelos ordenamentos latino-americanos, como nas constituições da Colômbia, Equador e Bolívia. Este artigo mostra como a reclamação do frade deve ser estendida a todos os seres humanos que sofrem violência, fome, escravidão, tortura e morte, quer dizer, para todos aqueles que sofrem violação dos direitos humanos.

Palavras-chave: Montesinos, leis de Índias, Direitos dos Povos Indígenas, liberdade, neoconstitucionalismo, constituições da América, direito à história. 


\section{INTRODUCCIÓN}

La historia de las ideas es también la historia de las sociedades. El historiador alemán Karl Mannheim (1993) aceptaba que se hace historia de las ideas siempre y cuando el historiador las contextualice con aquello que las posibilita, es decir, con los contextos sociales; solo así, afirmaba, es posible ver su impacto. Las ideas logran sensibilizar las conciencias y movilizar a los pueblos; algunas veces se convierten en utopías, no como algo irrealizable e irreal, sino como una anticipación de la realidad, es decir, como algo posible y deseable. “¿Para qué sirven las utopías?", le preguntaron a Eduardo Galeano en 1993, y él respondió: "Para echar a andar los pueblos".

Este breve ensayo seguirá la huella en el tiempo de una narrativa, creada a partir de un sermón que se convirtió en fuerza movilizadora para la sociedad. Para ello, se presentarán doce momentos históricos en los que es posible encontrar la voz de Montesinos, su narrativa y la de los primeros frailes dominicos que llegaron a la isla La Española, en 1509.

\section{El CONTEXTo}

Para Hosbawn (1974), historiador inglés, las ideas son fruto de su época; es cierto, pero algunas han resistido en el tiempo, hasta lograr, en su momento, una oportunidad para transformar a las sociedades. Las ideas de la comunidad dominicana expresadas por la voz del fraile Antón de Montesinos es un ejemplo de perdurabilidad en el tiempo y el espacio, convirtiéndose en vida y dignidad.
Las ideas expresadas por el fraile Montesinos en el sermón Yo soy una voz que clama en el desierto, también conocido como el Sermón de Adviento, tomado del Evangelio de San Juan (Juan 1, 23), reflejan el pensamiento de la pequeña comunidad dominicana asentada en la isla La Española. Montesinos llegó a estas tierras en septiembre de 1510 , junto con sus hermanos dominicos: fray Pedro de Córdoba, fray Bernardo de Santo Domingo y fray Domingo de Villamayor. Son los primeros miembros de esta orden religiosa en llegar a las tierras de Nuestra América. Educado en el Convento de San Esteban, en la ciudad de Salamanca, predicó los célebres sermones del 21 y 28 de diciembre de 1511. No habían pasado dieciséis meses de su llegada a estas tierras y ya los frailes no podían seguir guardando silencio ante la situación de extrema crueldad en que los españoles tenían sometidos a los nativos.

\section{EL SERMóN (LA NARRATIVA)}

Esta voz, dijo él, que todos estáis en pecado mortal y en él vivís y morís, por la crueldad y tiranía que usáis con estas inocentes gentes. Decid, ¿con qué derecho y con qué justicia tenéis en tan cruel y horrible servidumbre a estos indios? ¿Con qué autoridad habéis hecho tan detestables guerras a estas gentes que estaban en sus tierras mansas y pacíficas, donde tan infinitas de ellas, con muertes y estragos nunca oídos, habéis consumido? ¿Cómo los tenéis tan opresos y fatigados, sin darles de comer ni curarlos en sus enfermedades, que de los excesivos trabajos que les dais incurren y se os mueren, y por mejor decir, los matáis, 
por sacar y adquirir oro cada día? ¿Y qué cuidado tenéis de quien los doctrine, y conozcan a su Dios y creador, sean bautizados, oigan misa, guarden las fiestas y domingos? ¿Estos, no son hombres? ¿No tienen almas racionales? ¿No estáis obligados a amarlos como a vosotros mismos? ¿Esto no entendéis? ¿Esto no sentís? ¿Cómo estáis en tanta profundidad de sueño tan letárgico dormidos? Tened por cierto, que en el estado [en] que estáis no os podéis más salvar que los moros o turcos que carecen y no quieren la fe de Jesucristo (De Las Casas, 1586).

Poco se sabe de la vida del fraile después del sermón, se dice que este ilustre hombre murió mártir en Venezuela por los años de 1540, pero sus ideas y los de aquella pequeña comunidad dominica se multiplicaron.

\section{NaCe UN Gigante}

En un rincón del templo, un hombre escucha pensativo, angustiado, extasiado; sus manos sudan; él recuerda a los indígenas que bajo su orden trabajan de sol a sol en las minas de oro; recuerda sus rostros cansados, sus cuerpos desnudos, muy delgados, escucha su llanto, su miseria, su desesperación. La voz de Montesinos retumba en sus oídos con la fuerza de un volcán: “Estos, ¿no son hombres?” (De Las Casas, 1586). Este hombre que arribó a las Indias en 1503 en calidad de encomendero y se desempeñó extrayendo oro bajo el mando de Nicolás de Ovando, en la isla La Española, él como muchos españoles, llegó a estas tierras con sueños de riqueza. Sus ojos están húmedos, su garganta ahoga un gemido de dolor, estaba naciendo un gigante; este hombre era Bartolomé de Las Casas.

Al final del sermón, los rostros de los españoles se desfiguraron por el desconcierto, por la humillación, por la rabia: ¿con qué derecho este fraile los acusaba?, ¿quién se creía? Así describió este momento, para la historia, Bartolomé de Las Casas en su Historia de Indias (1586):

Finalmente, de tal manera explicó la voz que antes había muy encarecido, que los dejó atónitos, a muchos como fuera de sentido, a otros más empedernidos y algunos algo compungidos, pero a ninguno, a lo que yo después entendí, convertido.

En esto sí se equivocó De Las Casas: claro que inmediatamente después del sermón sí hubo un convertido: él mismo. En Pentecostés de 1514, De Las Casas renunció públicamente a sus encomiendas y empezó a predicar contra aquel sistema. Después, como miembro de la Orden de los Predicadores, la misma de Montesinos, transcribió y recuperó, en el capítulo 3, tomo III de la Historia de las Indias, para la historia y el futuro de la humanidad, el célebre sermón, convirtiéndose en el más aguerrido defensor de los indios de estas tierras y en un cronista excepcional.

¿Cómo resumir la vida de De Las Casas? En palabras de la historiadora Rand Parish (2002), “en total, Bartolomé de Las Casas consumió 'cincuenta años mortales', dirigiendo quizás el mayor esfuerzo para los derechos civiles y la justicia racial en la historia de la humanidad" (p. 56). Mucho se puede hablar de la vida de Bartolomé de Las 
Casas; se deben recordar las anotaciones de Beuchot (1994) y la tesis de la historiadora Barret Kriegel (1989), para quien "los derechos humanos no se inician con el iusnaturalismo ilustrado de la Revolución francesa, sino con el iusnaturalismo escolástico de la Escuela de Salamanca, singularmente, en Bartolomé de Las Casas. La historia confirma que los pioneros de este pensamiento son, sin duda, esa comunidad dominicana, quienes en 1511 eligieron a fray Antón para proclamar el sermón que proclama la lucha de los derechos humanos.

El padre Carlos Mario Álzate Montes, historiador de la Orden de Predicadores, en su ponencia "Las Casas y las corrientes de pensamiento dentro de la Orden en la conquista de América", presentada en el VIII Congreso de Historiadores Dominicos dedicado a la influencia lascasiana en el siglo XVII, señala que ante toda la información que existe de la obra lascasiana, hay que ser juicioso al sistematizar y analizar esta obra:

\section{Cuando hay un gran legado bibliográ- fico sobre el mismo objeto de estudio, conviene detenerse sobre este, pues de lo contrario se corre el peligro de caer en un círculo vicioso de lugares comu- nes, valga decir, la leyenda áurea o el ataque a España (Alzate, 2006, p. 8).}

Los expertos sostienen que con el sermón de Montesinos nacieron los derechos humanos en Nuestra América. Acerca del debate sobre dónde y cuándo nacieron los derechos humanos, nos dice Bobbio (1991): “Los derechos humanos nacieron donde pudieron, sabemos que no todos nacieron en el mismo tiempo y lugar". De tal suerte, atendiendo el llamado del célebre profesor italiano, fallecido en 2004, se puede decir que muy seguramente muchos derechos nacieron de la Escuela de Salamanca; otros, mucho antes; algunos tuvieron que esperar hasta el triunfo de la Revolución francesa; otros, más tiempo aun, del seno de la Organización de Naciones Unidas y la Organización de Estados Americanos; desde luego, muchos otros están por nacer. Los derechos humanos nacieron con la piel negra, morena, mulata, blanca, cobriza, amarrilla; por eso son universales, no nacieron en un mismo sitio a la misma hora. Evidentemente, los derechos de los pueblos indígenas pudieron haber nacido con este celebre sermón.

\section{Montesinos y De las Casas, LA NARRATIVA CONVERTIDA EN NORMA: LAS LEYES NUEVAS DE INDIAS}

Las palabras de Montesinos se convirtieron por primera vez en derecho positivo, en leyes, por la acción incansable de Bartolomé de Las Casas en 1542. La Junta Magna en Valladolid aprueba las famosas Leyes Nuevas de Indias, en las que por primera vez la Corona española censura y castiga el maltrato, la muerte y la esclavitud de los indígenas; este es uno de los logros más importantes de este sermón: llegar al corazón del monarca español Carlos I.

Algunos de los aspectos de estas Nuevas Leyes, donde se evidencia claramente la influencia del sermón de Montesinos y los primeros frailes dominicos, son:

- Cuidar la conservación, gobierno y buen trato de los indios. 
- Promover que no hubiera causa ni motivo alguno para hacer esclavos, ni por guerra, ni por rebeldía, ni por rescate, ni de otra manera alguna. Que los esclavos existentes fueran puestos en libertad, si no se mostraba el pleno derecho jurídico a mantenerlos en ese estado.

- Velar porque se acabara la mala costumbre de hacer que los indios sirvieran de cargadores sin su propia voluntad y con la debida retribución.

- Hacer que no fueran llevados a regiones remotas con el pretexto de la pesca de perlas.

- Hacer que los oficiales reales (del virrey para abajo) no tuvieran derecho a la encomienda de indios, lo mismo que las órdenes religiosas, hospitales, obras comunales o cofradías.

- Promover que el repartimiento dado a los primeros conquistadores cesara totalmente a la muerte de ellos y los indios fueran puestos bajo la Real Corona, sin que nadie pudiera heredar su tenencia y dominio.

Posteriormente, en 1539, Francisco de Vitoria, otro fraile dominico, pronuncia una lección sobre la colonización, en la que concluye que la independencia y soberanía de los estados eran inviolables, asimilando como tales a las naciones indias de Nuestra América. Vitoria es considerado hoy día como uno de los padres del derecho internacional.

\section{El SERMón CONTINÚA SU RECORRIDO CONVERTIDO EN ESPERANZA Y RESISTENCIA}

Las ideas que plasma el sermón alimentaron las esperanzas y los sueños de libertad de miles de personajes, muchos de ellos olvidados por la historia. Es el ejemplo de don Diego de Torres, cacique de Turmequé, quien en 1584 escribió su célebre Memorial de agravios, otro documento pionero en estas tierras sobre los derechos de los pueblos indígenas. Don diego, hijo del encomendero don Juan Torres y de la noble indígena Catalina Moyachoque, cursó su educación superior de gramática, religión, moral y derecho en el convento de los padres dominicos de Tunja, donde escuchó con especial atención la voz de Montesinos y de Bartolomé de Las Casas. Allí aprendió lo ordenado por las Nuevas Leyes de Indias.

El Memorial de agravios fue presentado en 1584 ante el rey Felipe II de España y fue reconocido en su época como un documento de gran calidad jurídica, incluso por celebres eruditos castellanos, lo que le valió al cacique Rumerqueteba el reconocimiento de miembros influyentes de la corte del monarca español. Este puede ser considerado el primer documento jurídico de exigibilidad de los derechos de los indígenas, hecho por los ellos mismos desde una perspectiva propositiva y resolutiva (Fajardo, 2007). Este Memorial puede ser otra de las consecuencias de la narrativa del fraile Montesinos, ya que inicia con la misma idea de aquel célebre sermón: 
Relación que Don Diego de Torres, Cacique, hace a su majestad sobre agravios que a los naturales del Nuevo Mundo se hacen por las personas en quienes su Majestad los tiene encomendados y de la manera que se consumen y acaban, las cosas que conviene remediar y el poco fruto que con ellos se ha hecho en su conversión... (Torres, 1986, p. 56).

En los veintiún puntos del Memorial, Rumerqueteba, su nombre chibcha, utiliza cada una de las leyes que la Corona tiene prevista para la defensa de los naturales, e incluso esgrime con gran habilidad los preceptos bíblicos para argumentar los derechos de sus hermanos indígenas. El conocimiento del derecho español le permite hacer una minuciosa descripción de las violaciones a los derechos de las comunidades indígenas y proponer, desde el mismo derecho del conquistador, soluciones o remedios e incluso hacer destituir regentes y miembros de la Audiencia Real de Santafé. Los puntos centrales de sus alegatos fueron:

- En lo que toca a la doctrina que se hace a los indios y el fruto que se ha hecho y se hace;

- Sobre que los indios han sido muy engañados en el tributo que han de dar a los españoles;

- Sobre que no se han tasado los indios conforme a la voluntad de su Majestad y el agravio que se les ha hecho;

- De cómo son maltratados los pueblos que son de V.M. que los otros que no lo son;
- De cómo los indios no son tratados como personas libres como lo son y como V.M. manda;

- De una manera de criar hijos de españoles en mucho perjuicio de los indios;

- De cómo las Ordenanzas Reales solamente se entienden con los que no tienen indios porque el que los tiene y posee en encomienda se sirve dellos como si fueran esclavos;

- De una contratación que hay de indios llevándolos los españoles a vender a otras provincias contra lo ordenado por V.M.;

- De cómo los encomenderos se han inventado mil géneros de servicios personales acabando con los indios;

- De cómo los naturales del Río Grande de la Magdalena se han acabado y se empiezan a acabar en otras provincias;

- Sobre la conveniencia de no tener nuevos corregimientos;

- De cómo son oídos los indios por la Real Justicia cuando se van a quejar a la Real Audiencia;

- De un agravio que particularmente se hace a los caciques sobre los tributos que han de pagar sus naturales;

- Del perjuicio que los indios han recibido en haberles encomendado a personas no beneméritas y cómo ni 
más ni menos ha sido V.M. engañada en esto;

- De cómo los licenciados Auncibay, Cetina y Mesa robaron a los naturales sus haciendas;

- De cómo ordenaros a los míseros indios más oro sin ellos tenerlo;

- De una orden que se dio para que los indios se alquilasen y el engaño que en ellos se hace a los pobres indios;

- De cómo la tierra quedó en mayor opresión que jamás ha estado por las prisiones de los jueces;

- Satisfacción que se solicita por los agravios a los indios;

- De cómo los indios son engañados por ser miserables y simples;

- Otros engaños que hacen a los indios para hacer tributos (Fajardo, 2003).

El historiador boyacense Ulises Rojas Soler, en su texto El cacique Turmequé y su época, relata la vida y obra de este indígena que escribió sus alegatos en el año de 1584 y ha sido considerado como el precursor universal de los derechos de los pueblos indígenas; había transcurrido setenta y tres años desde el célebre sermón de Montesinos. Don Diego, después de una penosa travesía a mediados del siglo XVI, llega a España en dos ocasiones a entrevistarse con el Monarca Don Felipe II (Soler, 1965, p. 67). Rumerqueteba muere mendigando en las calles de Madrid, España, el 4 de abril de 1590, hace 421 años.

\section{La voz de Montesinos, entre MUCHAS VOCES, SE ESCUCHÓ EN la UNIVERSIDAd SANTo ToMás $Y$ MUCHAS UNIVERSIDADES DE Nuestra América}

En muchas universidades y conventos de Nuestra América se tejieron sueños de libertad. Estos eran regentados por comunidades religiosas como los jesuitas, franciscanos y dominicos. En estos claustros fueron educados indígenas de la talla de Túpac Katari, Túpac Amaru, Jacinto Canek, Juan Santos Atahuallpa, entre otros, quienes desafiaron el poder colonial.

En los claustros de la tomística (hoy Universidad Santo Tomás), entre los años 1794 y 1795, según lo relata el investigador y maestro Alberto Cárdenas Patiño (2010), en su reciente trabajo El Papel de la Universidad Santo Tomás en la gesta independentista, citando al historiador Tisnés, señala:

\footnotetext{
Se tienen allí juntas secretas en pos de "la revolución" y discusiones acerca de la libertad [...] además en las noches se elaboran pasquines antigubernamentales en prosa y en verso, que amanecen fijados en sitios céntricos de Santafé (p. 56).
}

Señala el profesor Cárdenas que "los jóvenes tomistas manejaban los mismos textos jurídicos-políticos de Santo Tomás, Vitoria, Cano, Soto", y sin duda alguna, para estos criollos que buscaban sus raíces americanas, fueron lecturas principales los textos de De Las Casas y Montesinos, que permanentemente se editaron por la universidad y convivieron, en este claustro, con las nacientes ideas liberales que llegaron desde Francia. 
Ilustres tomasinos son Camilo Torres, Francisco de Paula Santander, Atanasio Girardot y Francisco José Caldas, quienes recibieron sus títulos de la Tomística y fueron considerados como próceres de la independencia grancolombiana.

Ya en 1781, el fraile Ciriano de Archila de la Orden de Predicadores, oriundo de Simacota, Santander, provincia comunera, había señalado el camino de la libertad al apoyar sin reparos la causa comunera y proclamar la necesidad de nuevos derechos y el fin de la tiranía. Casi treinta años después, el 20 de julio de 1810, el rector de la Pontifica y Regia Universidad, fray Mariano Garnica, estampa su firma en el Acta de la Independencia, y seguramente Montesinos y De Las Casas dieron firmeza a su puño al momento de estampar su rúbrica.

Al final del texto, el profesor Cárdenas (2010) nos recomienda "aprovechar la historia", que "consiste en aprovechar las claves de la memoria para convertirlas en lente de aproximación". Y continúa el autor: "Sin duda que interesa la 'utopía' pero en sentido de 'eu-topía' como proyecto optimista que prolonga las fortalezas y oportunidades del presente" (p. 56)

\section{La Declaración Universal de los Derechos de los Pueblos Indígenas}

Si se utilizaran las categorías del tiempo histórico propuestas por el historiador francés de la Escuela de las Anales: Fernand Braudel (2006), diríamos que esta narrativa de Montesinos y la primera comunidad dominicana en tierras americanas es una idea de larga duración histórica que corresponde, según el autor, a hechos estructurales que transforman de manera radical a los hombres y sus sociedades. Afirma Braudel que muchas veces los historiadores se dedican a relatar acontecimientos coyunturales, es decir, lo que el autor llama "tiempos históricos de corta duración, que no son más que la espuma en la ola de la historia". El autor recomienda analizar la historia desde una perspectiva de "larga duración", es decir, la evolución de los grandes procesos humanos, de las luchas de la humanidad por la dignidad, y qué mejor ejemplo de una historia de "larga duración" que ver en el tiempo, cinco siglos, la evolución de las ideas expresadas en el sermón del fraile Montesinos.

Después de veintidós años de discusión en el seno de las Naciones Unidas, el 14 de septiembre de 2007, la Asamblea General de la Organización de Naciones Unidas aprobó, por una votación de 143 Estados a favor, la Declaración Universal de los Derechos de los Pueblos Indígenas. 370 millones de indígenas de todo el mundo trabajaron juntos con miles de personas, organizaciones no gubernamentales, representantes de los estados y expertos para lograr por primera vez en la historia de la humanidad un instrumento que definiera los derechos inalienables y ancestrales de los pueblos indígenas. Habían pasado 496 años del sermón de Montesinos y su voz estaba más presente que nunca es estas sesiones. La Organización Indígena de Colombia en sus discusiones hizo alusión, en el seno de las Naciones Unidas, a este sermón, señalando que el fraile dominico había iniciado este largo camino que duró casi quinientos años en 
convencer a la humanidad sobre los derechos de los pueblos indígenas.

La declaración precisa los derechos colectivos e individuales de los pueblos indígenas; especialmente sus derechos a la tierra, bienes, recursos vitales, territorios y recursos; a su cultura, identidad y lengua; al empleo, la salud, la educación; y a determinar libremente su condición política, su desarrollo económico y la consulta previa.

\section{Algunas consideraciones de la Declaración de la ONU}

Reconociendo y reafirmando que las personas indígenas tienen derecho sin discriminación a todos los derechos humanos reconocidos en el derecho internacional, y que los pueblos indígenas poseen derechos colectivos que son indispensables para su existencia, bienestar y desarrollo integral como pueblos,

Preocupada porque los pueblos indígenas hayan sufrido injusticias históricas como resultado, entre otras cosas, la colonización y enajenación de sus tierras, territorios y recursos, impidiéndoles ejercer, en particular, su derecho al desarrollo de conformidad con sus propias necesidades e intereses,

Reconociendo la urgente necesidad de respetar y promover los derechos intrínsecos de los pueblos indígenas, que derivan de sus estructuras políticas, económicas y sociales y de sus culturas, tradiciones espirituales, historias y filosofías, especialmente los derechos a sus tierras, territorios y recursos,
Reconociendo además la urgente necesidad de respetar y promover los derechos de los pueblos indígenas afirmados en tratados, acuerdos y otros arreglos constructivos con los Estados,

Acogiendo con beneplácito el hecho de que los pueblos indígenas se estén organizando para promover su desarrollo político, económico, social y cultural y para poner fin a toda forma de discriminación y opresión dondequiera que ocurran,

Convencido de que el control por los pueblos indígenas de los acontecimientos que afectan a ellos ya sus tierras, territorios y recursos les permitirá mantener y reforzar sus instituciones, culturas y tradiciones, y promover su desarrollo de acuerdo con sus aspiraciones y necesidades,

Reconociendo también que el respeto de los conocimientos, las culturas y prácticas tradicionales indígenas contribuye al desarrollo sostenible y equitativo ya la ordenación adecuada del medio ambiente,

Destacando la contribución de la desmilitarización de las tierras y territorios de los pueblos indígenas a la paz, el progreso económico y social y el desarrollo, la comprensión y las relaciones amistosas entre las naciones y los pueblos del mundo,

Reconociendo en particular el derecho de las familias y comunidades indígenas a seguir compartiendo la responsabilidad por la crianza, formación, 
educación y bienestar de sus hijos, en consonancia con los derechos del niño,

Considerando que los derechos afirmados en los tratados, acuerdos y arreglos constructivos entre los Estados y los pueblos indígenas son, en algunas situaciones, asuntos de preocupación, interés, responsabilidad y carácter (Declaración Universal de los Derechos de los Pueblos Indígenas, Organización de Naciones Unidas).

El Gobierno colombiano, en cabeza del presidente Álvaro Uribe Vélez, que inicialmente había decidido votar a favor de la Declaración, a último momento se abstuvo. Nadie entendió por qué sucedió esto. Luis Evelis Andrade, presidente de la Organización Indígena de Colombia, afirmó que la abstención del gobierno nacional fue una respuesta de rechazo a las multitudinarias marchas indígenas del sur del país, exigiendo el derecho a la consulta previa frente a los proyectos mineros, petroleros, agroindustriales y de infraestructura a desarrollar, la mayoría por empresas transnacionales, en los territorios de nuestros pueblos indígenas. Una gran marcha por la paz se dio un mes antes de la votación en la Asamblea de la Organización de Naciones Unidadas y participaron más de 15.000 indígenas (Fajardo, 2009).

Las voces de Montesinos, Vitoria, De Las Casas, Don Diego de Torres y muchos más se unieron a las voces de millones de personas de todo el mundo que apoyaron la aprobación de esta declaración.

\section{LA VOz DE Montesinos: LOS DERECHOS DE LOS PUEBLOS INDÍGENAS EN LAS CONSTITUCIONES DE LOS PAÍSES de Nuestra América}

Muchos de los avances respecto de los derechos de los pueblos indígenas se han concretado bajo un nuevo enfoque constitucional. En los países de Nuestra América inicia a comienzos de los años noventa. Los estudiosos del tema han llamado a este fenómeno de la constitucionalización de la vida social como neoconstitucionalismo.

El neoconstitucionalismo es una de las doctrinas derivadas del constitucionalismo moderno - surgidas en Europa-, la cual ha influenciado progresivamente América Latina en la década de los años noventa y algunos países africanos:

Está interesado especialmente en una
parte de la problemática constitucio-
nal, la relacionada con la protección
y garantía de los derechos humanos.
En cambio, presta menor atención a
la organización estatal, a la denomina-
da "parte orgánica". Su meta no es tan-
to limitar y controlar al poder (objetivo
central del constitucionalismo), como
afianzar y garantizar la vigencia de los
derechos humanos" (Santiago, 2008,
p. 34).

Históricamente, esta corriente doctrinaria encuentra su oportunidad luego de la Segunda Guerra Mundial, debido a que se vio la necesidad de emprender una restructuración de la teoría constitucional para que esta norma no solo fuese legalmente promulgada, sino justa, eficaz y operativa. Estas ideas 
se fueron materializando, inicialmente, en la constitución de la posguerra de Alemania, con la sanción de la llamada Ley Fundamental para la República Federal de Alemania, en 1949. El Tribunal Constitucional Alemán surge posteriormente en 1951. En 1947 se aprueba la Constitución Italiana y su Corte Constitucional en 1956, continuando así esta expansión doctrinaria influyendo países como Francia, Portugal y España.

Se hizo realidad lo que hasta el momento las instituciones jurídicas creían imposible: las garantías constitucionales ya no eran potestades abstractas por hacerlas depender de la voluntad política; esa armadura milenaria con que se defendía el derecho, la Constitución, sería utilizada y defendida por primera vez por un guardián con grandes poderes: el tribunal constitucional. Como lo ha señalado Barroso (2008):

Las normas constitucionales estaban investidas de plena eficacia, que es la características de las normas jurídicas, y su no observancia ha de movilizar los mecanismos propios de coacción, o sea, de cumplimiento forzado (p. 35).

Es decir, no solo imprimió en los ordenamientos la transformación de la concepción normativa tradicional, sino que el cambio de paradigma ontológico tenía como fundamento la promoción del activismo judicial, planteando que la función que los jueces está llamada a realizar una democracia constitucional que debía traspasar los caminos de la interpretación en la concepción clásica, hacia la legislación activa (Aldunate Lizana, 2010).
Las potestades del juez crecían mientras más ordenamientos jurídicos se unían en esta causa; las constituciones dieron luz a aquellos hombres y mujeres que portaban la investidura de la justicia, y los transportaron tan alto como estos necesitaron para materializar los derechos: "Ellos han sido protagonistas y artífices de una creciente concientización y protección de los derechos humanos en nuestras democracias constitucionales" (Santiago, 2008, p. 40).

Una transformación que implicaba una transición del Estado de derecho al Estado constitucional de derecho o, por así decirlo, a un verdadero Estado social de derecho, en donde se garantizaran los postulados constitucionales; el desarrollo constitucional debía alcanzar mayor profundidad según la concepción de dignidad humana, al incluir principios rectores y los derechos fundamentales, junto con eficaces mecanismos de exigibilidad.

Particularmente, esta teoría constitucional se introdujo en el ordenamiento jurídico colombiano a partir de la Constitución de 1991, según la cual la nación colombiana es un Estado social de derecho, basado en el respeto de la dignidad humana, por el que todo colombiano tiene derecho a ella sin distinción de raza, sexo, edad, religión, pues todos somos iguales ante la ley y todos gozamos de la misma protección por parte del Estado.

Esta exaltación del individuo, otorgada por el ordenamiento, no solo dotó de derechos a los hombres y mujeres, en plena igualdad, reconociendo sus diferencias, sino que otorgó a los ciudadanos acciones concretas para alcanzarlos, estipulando que la constitución 
es norma de normas y concediendo a la judicatura del poder suficiente para el ejercicio de su independencia, lo anterior emanado del artículo 228:

\section{La Administración de Justicia es función pública. Sus decisiones son indepen- dientes. Las actuaciones serán públicas y permanentes con las excepciones que establezca la ley, y ellas prevalecerán el derecho sustancial. Los términos pro- cesales se observarán con diligencia y su incumplimiento será sancionado. Su funcionamiento será desconcentrado y autónomo.}

La Corte Constitucional colombiana, desde su instalación el 17 de febrero de 1992, ha tenido el papel protagónico en la transformación del régimen jurídico con tendencia colonial conservadora; de ahí que nuestro actual régimen esté impregnado de avances en cuanto a la concepción de igualdad y pluralismo étnico, libertad religiosa e individuales, el aborto, la eutanasia, los derechos de parejas del mismo sexo, los límites al ejecutivo y legislativo (Fajardo, 2009).

Una reciente investigación demuestra el sentido progresista de la Corte Constitucional, denominada por sus autores como "La segunda Corte de Oro"; en ella, incluso, se desarrollan los postulados de las llamadas escuelas críticas del derecho. En este sentido, la búsqueda de la inclusión, la lucha contra la pobreza, el multiculturalismo, el pluralismo jurídico, la participación, la defensa de los derechos económicos sociales y culturales han tenido avances importantes en la jurisprudencia:
El impacto de la jurisprudencia de esta "Segunda Corte de Oro" resulta fundamental, pero su efecto en la vida de millones de personas en el país es limitado. Se debe tener en cuenta que esta Corte Constitucional (1991-2001) ha actuado en el contexto de un país con unas instituciones políticas de piedra, un sistema judicial de papel y un sistema económico gaseoso, altamente inflamable. Lo que hemos llamado el efecto Gulliver, una Corte gigante en un país de instituciones liliputienses (Fajardo, 2009, p. 230).

La garantía de los derechos humanos ha llevado a la Corte Constitucional colombiana a "enfrentarse" con las otras altas cortes, como son el Consejo de Estado, la Corte Suprema y el Consejo Superior de la Judicatura, órganos de cierre de sus respectivas jurisdicciones, pero que en sus decisiones, al decir de la Corte Constitucional, pueden violar derechos fundamentales, teniendo que ser revisadas por el tribunal constitucional e, incluso, dejarlas sin efecto o revocándolas:

\footnotetext{
A la pregunta de si debe haber tutela contra decisiones judiciales, la misma corte constitucional dio una respuesta negativa en sus iniciales providencias. Pero si hoy en día, por el fulgor popular que se le ha dado al tema por el juez político, es necesario mantener la tutela contra sentencias, su decisión final no puede salir de la rama, de la jurisdicción ordinaria, so pena minar el principio de autonomía judicial (Academia Colombiana de Jurisprudencia, 2009).
} 
En Colombia, el papel de la Corte Constitucional es fundamental para garantizar el Estado social de derecho; sin embargo, teniendo en cuenta el efecto vinculante de sus decisiones, se hace necesario que los magistrados estén asesorados por un grupo interdisciplinario, previo a la toma de sus decisiones, para procurar que estas se fundarían ya no en relativas tendencias políticas y conceptos abstractos, sino en las condiciones reales del Estado colombiano.

\section{LA NARRATIVA DEL}

FRAILE MONTESINOS Y EL

"NACIMIENTO" DE UN NUEVO DERECHO HUMANO: EL DERECHO

\section{A LA HISTORIA}

Cada forma de conocimiento es respuesta a una realidad concreta y particular y a la historia de cada pueblo. Atribuir una forma de conocimiento sobre otra es también imponer una historia sobre la historia de otro pueblo. Bonfill (1992) al respecto comenta:

Frente a la idea [de que] la historia universal y única es la historia de Occidente, innumerables pueblos afirman que su historia es tan válida como cualquier otra, que la historia de Occidente expansionista y poderosa los influye pero no los determina inexorablemente; se puede convivir con Occidente y con los demás pero coexistir es eso: existir juntos, nunca existir una condición de renunciar a ser, un existir (p. 4).

Durante casi cinco siglos, la historia de los pueblos de Nuestra América quedó en manos de los historiadores europeos o americanos con pensamiento europeo; "en manos de los vencedores", como diría Eduardo Galeano (1984). A los pueblos "sin historia, sin memoria y sin sueños", los vencedores impusieron una historia, su historia. Hoy, por ejemplo, a los estudiantes de las facultades de derecho de Nuestra América les enseñan el derecho romano y griego y nada de sus propias formas de derecho ancestral como las indígenas, afrodescendientes y raizales. Coexistir, sí: Occidente es importante, pero lo nuestro también.

El sermón del fraile Montesinos señala un reclamo:
¿Con qué autoridad habéis hecho tan detestables guerras a estas gentes que estaban en sus tierras mansas y pací- ficas, donde tan infinitas de ellas, con muertes y estragos nunca oídos, habéis consumido?

Sí, nuestros pueblos ya estaban aquí cientos de años antes de que lo europeos llegaran; sin embargo, si leemos la historia de la mayoría de nuestros países, los temas relacionados con indígenas, afroamericanos, raizales, mestizos, gente humilde, etc., esta es muy reducida comparada con la abundante bibliografía de la historia de las élites blancas y los grupos de poder dominantes. La historia que nos han contado es solo una parte de la historia.

Los pueblos y comunidades indígenas de Nuestra América tienen un origen y un pasado común, lleno de desigualdad, discriminación y persecución. La situación de esas, tanto en la colonia como durante la creación de los Estados latinoamericanos hasta la actualidad, ha sido marcada por una continua 
exclusión y segregación, además de una constante violencia selectiva dirigida a sus principales líderes. Parece ser, entonces, que a pesar de los quinientos años del grito de Montesinos, en los territorios de Nuestra América, los pueblos indígenas siguen siendo víctimas de las más graves violaciones a los derechos humanos (Fajardo, 2007).

En la actualidad podemos decir que aunque no ha desaparecido la dura realidad en la que se sobreviven nuestras comunidades, sí se ha visibilizado su situación como consecuencia de los procesos de organización y resistencia que se ha adelantado durante más de cinco siglos:

\section{El surgimiento en los últimos años de pueblos indígenas como nuevos prota- gonistas sociales y políticos en Améri- ca Latina puede ser visto como un paso en la transformación del Estado y la transición a una nueva forma de vida, la democrática (Stavenhagen, 2002).}

Como resultado lógico de este nuevo papel de los indígenas dentro de sus sociedades, se evidencia, en la actualidad, un avance y un desarrollo significativo en la legislación y protección constitucional de los pueblos indígenas de la región (Fajardo, 2005). El proceso de transformación en relación con la legislación de los pueblos indígenas ha sido lento y diverso en los países de Nuestra América, ya que las garantías constitucionales y legales eran mínimas y las pocas que existían eran más formales que materiales:

Si bien la ciudadanía formal les fue garantizada en la mayoría de países poco después de la independencia, en algunos los indígenas fueron tratados hasta hace muy poco como menores y legalmente incapacitados. Solo en los últimos tiempos se modificaron leyes básicas al respecto, en el marco de las reformas constitucionales, incluyendo normas no solo en relación con las lenguas y culturas indígenas, sino también en algunos casos con respecto a las comunidades, sus territorios y formas específicas de vida (Stavenhagen, 2002).

Se analizarán muy brevemente las constituciones de Colombia, Ecuador y Bolivia, y cómo desde un enfoque neoconstitucional se produjeron cambios importantes en el reconocimiento de los derechos de los pueblos indígenas, consolidando de esta manera, en el plano material, los reclamos del fraile Antón de Montesinos quinientos años atrás. Es justamente a partir de enfoques neoconstitucionalistas que se ha ido tejiendo el nacimiento de este nuevo derecho fundamental en la historia, y es justamente en estas tres constituciones en donde se puede ver su consolidación con más fuerza.

\section{Bolivia}

La Constitución Boliviana de 2009 señala, como ninguna otra, la necesidad de recuperar la historia como base de la democracia. Insiste en que la refundación de la democracia y la nacionalidad pasa por reconocer los grandes crímenes que se cometieron contra la población indígena y negra. La historia se concibe como patrimonio de la democracia, como referente del futuro, como reconocimiento de las injusticias ancestrales y requisito para iniciar los procesos de reconciliación nacional. 
En el preámbulo de la Constitución Política de Bolivia, aprobada por el $65 \%$ de la población, se observa aquello que el pueblo boliviano reconoce:

Composición plural desde la profundidad de la historia, inspirado en las luchas del pasado, en la sublevación indígena anticolonial, en la independencia, en las luchas de liberación en las marchas indígenas y sociales (Constitución Política de Bolivia, 2009).

Este reconocimiento de la historia como hecho fundante del pluralismo proclama el papel predominante en la construcción de la nacionalidad boliviana que han tenido los pueblos y las comunidades indígenas y negras en todo el transcurrir de su historia como Nación y se expone, a su vez, el difícil camino que han afrontado para lograr la protección de sus derechos. La inclusión de los excluidos, pero también un llamado al reconocimiento de la diversidad étnica y cultural. Ese anhelo es uno de los contenidos materiales del derecho a la historia.

En suma, se reivindica el papel preponderante de la historia como un derecho fundamental de suprema protección para la sociedad, teniendo como resultado la creación de un nuevo Estado como principio de valoración humana y reconociendo la igualdad y las condiciones multiétnicas del país, como un medio para la superación de las exclusiones provenientes del pasado:

\footnotetext{
Construimos un nuevo Estado. Un Estado basado en el respeto e igualdad entre todos, con principios de soberanía, dignidad, complementariedad, solidaridad, armonía y equidad en la
}

distribución y redistribución del producto social, donde predomine la búsqueda del vivir bien; con respeto a la pluralidad económica, social, jurídica, política y cultural de los habitantes de esta tierra; en convivencia colectiva con acceso al agua, trabajo, educación, salud y vivienda para todos (Constitución Política de Bolivia, 2009).

Esta construcción trae consigo el fortalecimiento de las bases culturales de la nación, en donde sus principales pilares de protección se configuran como resultado de las luchas sociales y nuevamente se desarrolla el llamado del fraile Montesinos: “Jamás comprendimos el racismo hasta que lo sufrimos desde los funestos tiempos de la colonia". Ello conllevó el resurgimiento de un pueblo que florece, dejando atrás "el Estado colonial, republicano y neoliberal", cuyo fin es otorgar el poder a unos pocos y la pobreza para la mayoría de indígenas, afrobolivianos y campesinos de la nación:
Asumimos el reto histórico de cons- truir colectivamente el Estado Unitario Social de Derecho Plurinacional Comu- nitario, que integra y articula los pro- pósitos de avanzar hacia una Bolivia democrática, productiva, portadora e inspiradora de la paz, comprometida con el desarrollo integral y con la libre determinación de los pueblos (Consti- tución Política de Bolivia, 2009).

Todas estas Circunstancias "han hecho posible esta nueva historia", en la que el pueblo indígena boliviano olvidado y excluido es reconocido y protegido por un Estado, instaurándose como eje fundamental la diversidad de sus pueblos y garante de la 
igualdad, material de todos los bolivianos y bolivianas.

Siguiendo con el marco de referencia, en relación con los primeros artículos de la constitución boliviana relativos a la configuración del Estado, se encuentra que se da un gran reconocimiento a los pueblos y comunidades indígenas como miembros fundamentales de dicha organización estatal (artículos 1, 2, 3 de la Constitución Política de Bolivia). Se reconoce, a su vez, de manera general el respeto por las creencias y cosmovisión de los pueblos indígenas y la oficialidad de las lenguas autóctonas de los mismos. El capítulo 4 de esta Constitución está dedicado de forma exclusiva a los "derechos de las naciones y pueblos indígena y campesino". Allí se les reconoce de manera general a estas comunidades, entre otros, los siguientes derechos:

Existir libremente, identidad cultural, creencia religiosa, espiritualidades, prácticas y costumbres, propia cosmovisión, libre determinación y territorialidad, titulación colectiva de tierras y territorios, respeto de sus lugares sagrados, medio ambiente sano, propiedad colectiva de sus saberes, ejercicio de sus sistemas políticos jurídicos y económicos (Constitución Política de Bolivia, 2011, artículo 30).

En Nuestra América, en un hecho sin precedentes, se han adelantado las elecciones populares de magistrados del Tribunal Plurinacional de Bolivia. Este Alto Tribunal se creó por la reforma constitucional aprobada en 1994, y operativamente empezó a funcionar en 1999, luego de que los lineamientos constitucionales de su funcionamiento fueran establecidos por la Ley 1836 del 1 de abril de 1998 (Ley del Tribunal Constitucional). Actualmente es regulado por la Ley 027 de 06 de julio de 2010, o Ley del Tribunal Constitucional Plurinacional.

Uno de los temas que ha generado las críticas más ácidas de varios sectores en Bolivia es la forma de elección de sus magistrados, constitucionalmente prevista por elección popular, a partir de una lista previa de candidatos determinada por la Asamblea Legislativa Plurinacional, que es el Congreso de la República de Bolivia. El domingo 16 de octubre de 2011 se llevaron a cabo las primeras elecciones para escoger las altas autoridades judiciales bolivianas, entre las cuales se incluye a los magistrados del Tribunal Constitucional. Solo el 34\% del censo electoral boliviano acudió a las urnas. Fueron elegidos 56 autoridades judiciales (28 hombres y 28 mujeres), donde, por fin, después de quinientos años del célebre sermón de Fray Antón de Montesinos, tienen representación los indígenas y campesinos de esta nación.

\section{Ecuador}

Ecuador es otro país de Nuestra América con un alto porcentaje de población indígena; igualmente, en el orden jurídico constitucional, reconoce los derechos de dichos pueblos:

\footnotetext{
Si bien dentro de la normativa tanto constitucional como legal se produce una especie de igualdad formal, aquella se ve mancillada en la práctica, en donde una serie de variables operan para que se produzcan procesos de exclusión interna que se terminan
} 
convirtiendo en actos discriminatorios contra estas comunidades (Masapanta, 2009).

La Constitución Política de Ecuador en su preámbulo hace una importante referencia a la presencia y a los valores indígenas, haciendo un reconocimiento a las "raíces milenarias, forjadas por mujeres y hombres de distintos pueblos", así como al componente multicultural y diverso de las comunidades asentadas en su territorio, como forjadores de una historia, de un derecho, de un vivir que dio origen a la construcción del derecho preponderante.

"Apelando a la sabiduría de todas las culturas que nos enriquecen como sociedad..." (Constitución Política de la República del Ecuador, 2008). Con este reconocimiento se visibiliza la historia milenaria y sus formas de conocimiento no como hechos del pasado, sino como formas que permiten el diálogo de saberes para la construcción de una sociedad respetuosa e intercultural.

\section{Continúa la Constitución ecuatoriana:}

\footnotetext{
Como herederos de las luchas sociales de liberación frente a todas las formas de dominación y colonialismo, y con un profundo compromiso con el presente y el futuro, decidimos construir una nueva forma de convivencia ciudadana, en diversidad y armonía con la naturaleza, para alcanzar el buen vivir, el sumakkawsay; una sociedad que respeta, en todas sus dimensiones, la dignidad de las personas y las colectividades.
}

Asimismo, posteriormente determina, en la forma de organización del Estado, el carácter "intercultural y plurinacional" (Constitución Política del Ecuador, 2008, artículos 1 y 2). En dichos preceptos constitucionales se encuentra el fundamento de la aplicación por parte de los indígenas de sus propias formas jurídicas: "Precisamente la jurisdicción indígena responde a esta necesidad de respeto de las diferencias culturales existentes entre los diversos grupos sociales que conforman la sociedad Ecuatoriana" (Masapanta, 2009). A lo largo de la Constitución del Ecuador se evidencia el desarrollo de los principios de interculturalidad y plurinacionalidad, especialmente en los artículos “3.3, 10, 57, 60, 171 y 242, entre otros" (Masapanta, 2009).

Los pueblos indígenas del Ecuador tienen una serie de derechos tanto individuales como colectivos, los cuales tienen el fundamento de su protección en el artículo 57. Dichos derechos se resumen en la consulta previa, imprescriptibilidad y titularidad colectiva de sus tierras, el derecho al agua y a los recursos naturales y el derecho a administrar justicia dentro de una jurisdicción especial. En Ecuador, el Tribunal de Garantías Constitucionales (TGC) y la Sala Constitucional de la Corte Suprema de Justicia han tenido un papel muy importante en la protección de los derechos de los pueblos indígenas:

El funcionamiento del TGC y de la Sala Constitucional de la Corte suprema brindan a los indígenas la posibilidad de defender los actos dictados por las autoridades de gobierno en materia de reforma agraria, distribución del agua 
potable, venta de productos agrícolas, entre otros.

\section{Colombia}

Colombia es un país con una enorme riqueza jurídica. La esencia pluriétnica y multicultural de la nación tiene su reflejo en la diversidad jurídica. Dichos preceptos se establecieron en la Constitución de 1991, que se constituye como base normativa del ordenamiento jurídico, en la cual se instauraron condiciones taxativas y fundamentales de protección para las comunidades indígenas que habitan en el país.

Mediante el preámbulo, base de la Constitución del 1991, el constituyente estableció su intención:

Incorporar, mucho más allá de un simple mandato específico, los fines hacia los cuales tiende el ordenamiento jurídico"; convirtiéndose en "la motivación política de toda la normatividad; los valores que esa Constitución aspira a realizar y que trasciende la pura literalidad de sus artículos (Corte Constitucional, Sentencia 479/92).

Fortalecer la unidad de la Nación y asegurar a sus integrantes la vida, la convivencia, el trabajo, la justicia, la igualdad, el conocimiento, la libertad y la paz, dentro de un marco jurídico, democrático y participativo que garantice un orden político, económico y social justo (Constitución Política de Colombia, 1991).

Ahora bien, la vinculación normativa del preámbulo obedece a que establece los principios y fundamentos normativos bajo la cual se rige la Constitución, convirtiéndose en parte imperante en la protección de legados operantes en el sistema jurídico. Por ello, en la Sentencia 479 de 1992 el tribunal Constitucional Colombiano estipula en sus consideraciones el "poder vinculante" del preámbulo:
En cuanto sustento del orden que la Carta instaura y, por tanto, toda nor- ma - sea de índole legislativa o de otro nivel- que desconozca o quebrante cualquiera de los fines en él señalados, lesiona la Constitución porque traicio- na sus principios.

Al traer esta discusión que ha sido resuelta en Colombia, se puede concluir que, igualmente, por derecho comparado, los preámbulos de la constitución boliviana y la ecuatoriana, donde se reconoce la historia, siempre negada, de los pueblos indígenas y las comunidades afrodescendientes, tienen esa fuerza vinculante que la hace exigible. Es decir, con esta interpretación, el derecho a la historia es ya un derecho fundamental exigible y debe ser tutelada por sus respectivos tribunales constitucionales.

La Constitución Política de Colombia es generosa en reconocer a sus pueblos indígenas y demás grupos étnicos los derechos que históricamente se les habían negado y que fueron motivo del acalorado discurso del fraile dominico Antón de Montesinos el 21 de diciembre de 1511.

"El Estado reconoce y protege la diversidad étnica y cultural de la Nación Colombiana" (artículo 7) y "es obligación del Estado proteger las riquezas culturales" (artículo 8). 
Con estos artículos, el Estado busca garantizar el respeto efectivo a las costumbres y prácticas sociales de los grupos étnicos que comparten el territorio de Colombia; esto tiene como colofón el fortalecimiento de las propias comunidades, de sus autoridades y la recuperación de su historia y cosmovisión.

Pero también la Constitución establece una amplia gama de derechos cuya principal función es la protección de las comunidades indígenas en relación con la sociedad mayoritaria. Entre ellos tenemos: "Las lenguas y dialectos de los grupos étnicos son también oficiales en sus territorios, y en las comunidades con tradición lingüística propia la educación será bilingüe (artículo 10). "Su formación deberá respetar y desarrollar su identidad cultural" (artículo 68). "Las tierras comunales de grupos étnicos y las tierras de resguardo son inalienables, imprescriptibles e inembargables" (artículo 63). "Se reconoce que los grupos étnicos asentados en territorios de riqueza arqueológica tienen derechos especiales sobre esos patrimonios culturales, que deben ser reglamentados por ley" (artículo 72). "Reconoce como nacionales colombianos a los indígenas que comparten territorios fronterizos, a condición de reciprocidad" (artículo 96). "Crea cargos de senadores y un número a reglamentarse de hasta cinco representantes a elegirse en circunscripción nacional especial por comunidades indígenas" (artículo 176).

La Constitución Política de Colombia busca mediante estos artículos fortalecer los lazos étnicos; pretende, mediante el mandato constitucional, el desarrollo de los preceptos del Estado como multiétnico y multicultural, promoviendo el sostenimiento de los grupos étnicos que conforman la nación, respetando las particularidades de cada uno de estos pueblos: unidad en la diversidad.

Establece, además, que "las autoridades de los pueblos indígenas podrán ejercer funciones jurisdiccionales dentro de su ámbito territorial, de conformidad con sus propias normas y procedimientos, siempre que no sean contrarios a la Constitución y leyes" (artículo 246). Asimismo, esta autonomía ha sido reconocida por la Corte Constitucional y tutelada por el Estado desde 1994, mediante la Sentencia T-254, momento en que la Corte expuso:

Las comunidades indígenas son verdaderas organizaciones, sujetos de derechos y obligaciones, que por medio de sus autoridades ejercen poder sobre los miembros que las integran hasta el extremo de adoptar su propia modalidad de gobierno [...] Las comunidades indígenas no se equiparan jurídicamente a una simple asociación. Son una realidad histórica, dinámica, caracterizada por elementos objetivos y subjetivos que no se reducen al animus asociandis propio de las asociaciones civiles. Se nace indígena y se pertenece a una cultura, que se conserva o está en proceso de recuperación.

El acceso a la justicia es un derecho fundamental que es interpretado mediante diversos preceptos constitucionales, como lo es el derecho a la igualdad:

De acuerdo con la Constitución Política de Colombia, el derecho al acceso a 
la administración de justicia, a su vez debe darse en condiciones de igualdad [...] Sin embargo, el acceso a la justicia en comunidades negras/afrocolombianas, raizales y palenqueras tiene restricciones por dificultades de tipo geográfico, por las limitaciones de acceso al sistema de justicia, y también por las prácticas de exclusión y discriminación racial que afectan no solo el acceso a la justicia, sino también la aplicación y el desarrollo de sus sistema propio de administración de justicia (Conferencia Nacional de Organizaciones Afrocolombianas y Proceso de Comunidades Negras, 2010).

El artículo 55 transitorio de la Constitución Política, aunque sirve de herramienta para el reconocimiento de la identidad y de la tradición afrocolombiana, no es lo suficientemente amplio como en el caso de las comunidades indígenas:

Con relación al tema de la autonomía, esta no se encuentra edificada como así fue consagrada respecto de los grupos indígenas, toda vez que se limita el precepto superior a señalar la existencia de comunidades negras, poseedoras de prácticas tradicionales de producción, que entrañan la repetición de actos al interior de la colectividad que se erigen como obligatorios al momento de realizar ciertas conductas, derivadas de una conciencia colectiva (Procuraduría General de la Nación, 2004).

Esta creación constitucional ordena un desarrollo legislativo posterior muy importante para las comunidades afrocolombianas, el cual se materializa en la Ley 70 de 1993, que señala aspectos relevantes en relación con la autonomía, integridad y protección de estas comunidades: "Este proceso fue alimentado por el movimiento social afrocolombiano que en desarrollo del artículo 55 de la Constitución Política dio origen a dicha ley" (Parra y Rodríguez, 2005).

Es importante resaltar que a partir de la Ley 70 de 1993 y de dicho desarrollo jurisprudencial, se ha podido entender, en primer lugar, la importancia y la significación del concepto de comunidad negra y la justificación o fundamento de su protección, dentro del marco de la diversidad cultural:

La Ley 70 de 1993 define las comunidades negras como el conjunto de familias de ascendencia afrocolombiana que poseen una cultura propia, comparten una historia y tienen sus propias tradiciones y costumbres dentro de la relación campo-poblado, que revelan y conservan conciencia de identidad que las distinguen de otros grupos étnicos (Parra y Rodríguez, 2005).

De esto se puede establecer que el marco jurídico colombiano no llega a reconocer a las comunidades afrocolombianas como un sector de la población merecedor de protección y reconocimiento por la simple diferencia racial o biológica, sino por una serie de lazos sociales, históricos, políticos, económicos y religiosos, que construyen una identidad común a todos sus miembros.

La mayoría de las decisiones jurisprudenciales en relación con las comunidades afrocolombianas giran en torno al reconocimiento de la identidad de estas, a la no discriminación y al derecho a la igualdad. En relación 
con el derecho a la igualdad, la Corte Constitucional analiza una especial significación de este en la población afrodescendiente:

La carta política le ha reconocido a través de ley una igualdad promocional a la población afrocolombiana, la cual se debe entender en un orden general; es decir, que eventualmente beneficiaría a las comunidades negras de todo el país y no estaría simplemente ligada al reconocimiento de una especie de propiedad colectiva, justificada en una ocupación ancestral de partes del territorio nacional para hacer efectiva la igualdad promocional (Parra y Rodríguez, 2005).

Esta ley se convirtió así en una puerta para visibilizar la problemática de las comunidades afrocolombianas y generó un marco para la protección y garantía de los derechos y prerrogativas de estas. Esta ley es conocida como "la ley de comunidades negras, misma que promueve el respeto a los derechos humanos, sociales, políticos, territoriales, económicos y culturales de las comunidades afrocolombianas" (Parra y Rodríguez, 2005). Al respecto, Sánchez Botero (2004) reconoce:

En el tratamiento constitucional de las etnias hay una evidente jerarquización que recrea viejas subordinaciones que se han presentado históricamente. Así, hay reconocimiento y consagración de derechos de las distintas etnias, ya se trate de los indígenas, los negros y los raizales de San Andrés y Providencia. Lo anterior parece obedecer a dos razones fundamentales: A la historia misma de la luchas y conquistas de los grupos étnicos en Colombia y al interés especial pero jerarquizado, que en el contexto político, nacional e internacional, despierta la inclusión de lo étnico en la constitución colombiana (p. 94).

Se configuran así los derechos de los pueblos indígenas de autodeterminación y de creación de un sistema de disposiciones que configuran una forma propia de administrar justicia y con base en su cosmovisión, valores y tradiciones que conforman su entorno social, aunque dejando en la esfera de lo invisible otras comunidades tales como los afrocolombianos, que quedaron en situación de indefensión frente a los hilos operantes del Estado.

\section{CONCLUSIONES PARCIALES: VIGENCIA DE LAS PALABRAS DEL FRAILE MONTESINOS}

A pesar de los avances en la garantía de los derechos de los pueblos indígenas de Nuestra América, en las constituciones, especialmente en los tres países analizados, Colombia, Ecuador y Bolivia, la idea promulgada por la voz del fraile dominico Antón de Montesinos está lejos de la realidad. La denuncia del fraile es imposible entenderla sin hacerla extensiva a todos los seres humanos que sufren violencia, hambre, esclavitud, tortura y muerte, es decir, a todos aquellos que sufren violación de los derechos humanos.

Esta idea, enraizada en miles de personas estos quinientos años, tiene nuevos retos. El Informe Anual sobre Desarrollo Humano del PNUD para el 2010: “La verdadera riqueza de las Naciones: camino hacia el 
desarrollo humanos", señala que la pobreza y la desigualdad entre países desarrollados y países en vías de desarrollo ha aumentado dramáticamente. Los países pobres son cada vez más pobres. Igualmente, especifica la pérdida del ingreso de la mayoría de personas trabajadoras en el mundo. Alerta sobre las discriminaciones relativas al género, las exclusiones raciales, culturales y generacionales. La desigualdad en el mundo se refleja en casos tangibles como en Noruega; allí los indicadores se acercan a la unidad, con un índice de 0,938 en la primera posición, Zimbabue, ocupa el puesto 169 con un índice de 0,140; eEsto no significa otra cosa que hambre, pobreza, ausencia de derechos de los hombres y mujeres de este país.

El desarrollo humano está definido como el proceso por medio del cual una sociedad mejora y asegura las mejores condiciones de vida de sus ciudadanos a través de un incremento de los bienes con los que puede cubrir sus necesidades básicas y complementarias, y de la creación de un entorno en el que se respeten los derechos humanos de todos ellos (Fajardo, 2007).

Actualmente, el mundo tiene hambre, sí, los países ricos miran con indiferencia la muerte, por física hambre, de los países más pobres. Según el "Proyecto Hambre" de las Naciones Unidas, alrededor de 24.000 personas mueren cada día por hambre o por causas relacionadas con la pobreza; un $75 \%$ de los fallecidos son niños menores de cinco meses. El Instituto de Desarrollo y Política Alimentaria afirma que la hambruna y las guerras causan solo un $10 \%$ de las muertes por hambre, aun cuando tienden a ser de las que trascienden con mayor frecuencia. La mayoría de las muertes por hambre se deben a la desnutrición crónica. Las familias sencillamente no consiguen suficientes alimentos; esto, a su vez, se debe a la extrema pobreza.

Mientras que los gobiernos discuten sobre la macroeconomía de sus Estados y los escenarios ideales para el pleno desarrollo de las empresas multinacionales, hoy en el Cuerno de África se vive lo que la ONU ha definido como "tragedia humana de proporciones inimaginables". Unos 12,4 millones de personas en Somalia, Yibuti, Etiopía y Kenia y millones más en otros países vecinos tienen sus vidas amenazadas. Por una parte la hambruna, por otra la emergencia humanitaria. Una estimación hecha por el gobierno de Estados Unidos indica que en los últimos noventa días han muerto más de 29.000 niños menores de cinco años en el sur de Somalia.

Sin ir muy lejos, en Colombia hay cuatro millones de personas desplazadas por la violencia. Una cifra que no tiene comparación en el continente y pocas veces en el mundo; estos millones de personas para las cuales no hay derechos ni esperanzas, a pesar de la reiterada jurisprudencia de la Corte Constitucional a favor de estas personas.

La muerte de líderes sindicales se ha convertido en un hecho cotidiano, según noticia de la EFE:

El $60 \%$ de los sindicalistas asesinados en el mundo son colombianos, en 2010 cuando los asesinados fueron 49, de un total de 76 que, según la Confederación Sindical Internacional (CSI), murieron de manera violenta en todo el mundo (El Tiempo, 2010). 
La Corte Constitucional ha insistido, con una rica y generosa jurisprudencia, a favor de los derechos de los pueblos indígenas; recientemente denuncia este Alto Tribunal, en el Auto 004 de la Sentencia T-025, que más de treinta pueblos indígenas de nuestro país se encuentran al borde de la extinción física y cultural.

Otro asecto: la Fiscalía General de la Nación y la Procuraduría investigan entre 1200 y 1500 personas ejecutadas extrajudicialmente que fueron presentados como "falsos positivos". Hasta la fecha solo hay cuatro condenas judiciales de los miembros de la fuerza pública presuntamente responsables de estos hechos. Las madres y familiares de las víctimas han sido amenazados para que retiren las denuncias y son obligados a desplazarse.

Colombia es el país más minado del mundo: más de 8000 personas han sido víctimas de las minas antipersonal. Más de 500.000 niños colombianos, el 13\% de la población infantil, sufren de desnutrición crónica, según un estudio del Centro de Investigaciones de la Facultad de Economía de la Universidad de los Andes.

Mientras que los ciudadanos colombianos mueren siendo trasladados de hospital en hospital, en una práctica infame que se ha denominado "paseo de la muerte", el mismo gobierno denuncia que han sido saqueados por las empresas prestadoras de salud más de cuatro billones de pesos de ese sector. Hasta la fecha no hay ningún funcionario de estas empresas en investigación judicial por las muertes derivadas de este problema (Fajardo, 2010).
A pesar de estos quinientos años, por lo menos en nuestro país las palabras de Montesinos tienen plena vigencia. Muchas personas carecen de los mínimos vitales para sobrevivir con dignidad el desempleo, las nuevas formas de explotación laboral, el desplazamiento forzado, más de cuatro millones de víctimas del conflicto armado, etc.; por ello, vale la pena recordar la pregunta del fraile dominico:

\section{¿Cómo los tienen tan opresos y fati- gados, sin darles de comer ni curarlos en sus enfermedades? Estos, ¿no son hombres?, ¿no están obligados a amar- los como a ustedes mismos?}

\section{REFERENCIAS}

Aldunate Lizana, E. (2010). Aproximación conceptual y crítica al neoconstitucionalismo. Revista de Derecho, 23(1), 79-102.

Alvarado, M. (2009). Situación de las comunidades indígenas en Colombia. Revisión e iniciativa. Indepaz. Recuperado de http://docs.google.com/viewer?a=v\&q=cache:LeU9BlzBF88J:www.indepaz.org.co/ attachments

Alzate Montes, C. M. (2004). Las Casas y las corrientes del pensamiento dentro de la orden en la conquista de América. Salamanca: San Esteban.

Ariza, L. (2009). Derecho, saber e identidad indígena. Bogotá: Siglo del Hombre Editores - Universidad de los Andes - Pontificia Universidad Javeriana.

Barret-Krieguel (1989). Les droit de l'homme et le droit natural. París: PUF.

Barroso, L. R. (2008). El neoconstitucionalismo y la constitucionalización del derecho. El triunfo tardío del derecho constitucional en Brasil. 
Mexico: Universidad Nacional Autónoma de México.

Beuchot Puente, M. (1994). Bartolomé de Las Casas, el humanismo indígena y los derechos humanos. Anuario Mexicano de Historia del Derecho, 6, 37-48.

Bobbio, N. (1991). El tiempo de los derechos. Madrid: Sistemas.

Braudel, F. (2006). La larga duración. Revista Académica de Relaciones Internacionales, 5. Recuperado de http://www.relacionesinternacionales.info/ojs/article/view/53/47.html

Carbonell, M. (2008). Neoconstitucionalismo $\mathrm{y}$ derechos fundamentales en tiempos de emergencia. Estudios Constitucionales, 1, 249-263.

Cárdenas Patiño, A. (2010). Papel de la Universidad Santo Tomás en la gesta independentista. IUSTA, 33, 15-28.

Colmenares, G. (1938-1990). Melo, Jorge Orlando. Recuperado de http://www.banrepcultural.org/blaavirtual/historia/colonia3/9-1. htm

Conferencia Nacional de Organizaciones Afrocolombianas y Proceso de Comunidades Negras (2010). Plan de Acción en Derechos Humanos y DIH para la Comunidad Negra, Palenquera, Raizal y la Poblacion Afrocolombiana.

El Tiempo (2010, 4 de febrero). Asesinados 40 sindicalista el año pasado en Colombia, denuncia organización de trabajadores. Recuperado de http://www.eltiempo.com/ archivo/documento/CMS-7120268

Fajardo Sánchez, L. A. (1999). Multiculturalismo y derechos humanos. Bogotá: Escuela Superior de Administración Pública. .

Fajardo Sánchez, L. A. (2000). La Kriss Romani: el derecho de los gitanos. En Pensamiento jurídico (pp. 131-154). Bogotá: Universidad Nacional de Colombia.
Fajardo Sánchez, L. A. (2000). Una historia del anarquismo en Colombia. Crónicas de Utopía. Madrid: Madre Tierra.

Fajardo Sánchez, L. A. (2003). Las fuentes olvidadas del pluralismo jurídico en Colombia. Revista de Estudios Socio-Jurídicos. Bogotá: Universidad del Rosario.

Fajardo Sánchez, L. A. (2005). El derecho ancestral afrocolombiano. Los olvidos del multiculturalismo. En Otra justicia es posible. La justicia comunitaria como ruta para la democracia (pp. 155-188). Bogotá: Red de Justicia Comunitaria.

Fajardo Sánchez, L. A. (2006). Derecho y justicia en las aulas escolares. Bogotá: Universidad Santo Tomás. .

Fajardo Sánchez, L. A. (2008). El pensamiento intercultural y el derecho a la paz. En Filosofía, pensamiento intercultural y movimientos sociales en América Latina (pp. 201-136). Bogotá: Universidad Santo Tomás.

Fajardo Sánchez, L. A. (2009). Globalización y derechos humanos. IUSTA, 9, 3-37. Bogotá: Universidad Santo Tomás.

Fajardo Sánchez, L. A. y García Lozano, L. F. (2009). Utopía y jurisprudencia constitucional. Bogotá: Universidad Santo Tomás.

Fajardo Sánchez, L. A., Gamboa Martínez, J. C. y Villanueva Martínez, O. (1999). Manuel Quintín Lame y los Guerreros de Juan Tama (multiculturalismo, magia y resistencia). Madrid: Nossa y Jara Editores.

Fajardo Sánchez, L. A., Gamboa Martínez, J. C. y Villanueva Martínez, O. (1992). Biófilo Panclasta. El eterno prisionero. Bogotá: Alas de Xue.

Fajardo Sánchez, L. A., García Lozano, L. F. y Abondano Lozano, D. C. (2008). Los invisibles y la lucha por el derecho en Colombia. Bogotá: Universidad Santo Tomás. 
Galeano, E. (1984). Memorias del fuego (vol. II: Las caras y las máscaras). Madrid: Siglo XXI.

Galeano, E. (1993). Las palabras andantes (Ventana sobre la utopía). Bogotá: Siglo XXI.

Hobsbawm, E. (1974). Las revoluciones burguesas. Madrid: Guadarrama.

Las Casas, B. de (1986). Historia de las Indias. Caracas: Fundación Biblioteca Ayacucho.

Mannheim, K. (1936). Idealogy and utopia. Nueva York: Harcourt, Brace and conspany.

Mansilla, A. (2004). El derecho indígena y las pautas para la conformación de una línea jurisprudencial constitucional en Bolivia. Santa Cruz, Bolivia: Universidad Gabriel René Moreno. Recuperado de http://docs.google. com/viewer? $\mathrm{a}=\mathrm{v} \& \mathrm{q}=$ cache:j202yMTHvUAJ: www.uv.es/CEFD/10/mansilla.pdf+derecho $\mathrm{s}+$ constitucionales+de+los+pueblos+inidgen as+de+bolivia

Masapanta, C. (2009). El derecho indígena en el contexto constitucional ecuatoriano: entre la exigibilidad de derechos y el reconocimiento del pluralismo jurídico. Recuperado de http://www.juridicas.unam.mx/wccl/ponencias/7/120.pdf

Organización de Naciones Unidas (2007). Declaración Universal de los Derechos de los Pueblos Indígenas.

Organización de Naciones Unidas (2010). Proyecto Hambre.

Parra, C. y Rodríguez, A. (2005). Comunidades étnicas en Colombia. Cultura y Jurisprudencia. Bogotá: Centro Editorial Universidad del Rosario.

Procuraduría General de la Nación (2004). La diversidad étnica en Colombia: alcances y desarrollo. Bogotá: Grupo de Asuntos Étnicos de la Procuraduría General de la Nación.

Rand Parish, H. (2002), Biografía de Fray Bartolomé de las Casas. Recuperado de http:// www.ciudadseva.com/textos/estudios/casas/casas04.htm

República de Bolivia (1967-2008). Constitución Política de Bolivia.

República de Colombia (1991). Constitución Política de Colombia.

República de Colombia (1993). Ley 70 de 1993, por la cual se desarrolla el artículo transitoria 55 de la Constitución Política. Diario Oficial $n .^{\circ} 41.013$

República de Colombia, Corte Constitucional (1992). Sentencia 479 de 199. Magistrados ponentes: José Gregorio Hernández Galindo y Alejandro Martínez Caballero.

República de Colombia, Corte Constitucional (1994). Sentencia T-254 de 1994. Magistrado ponente: Dr. Eduardo Cifuentes Muñoz.

República de Colombia, Corte Constitucional (2010). Sentencia C- 063/2010.

República de Ecuador (2008). Constitución Política de Ecuador.

Rojas, U. (1965). El cacique de Turmequé y su época. Boyacá: Imprenta Departamental de Boyacá.

Sánchez Botero, E. (2004). Justicia y pueblos indígenas de Colombia. Bogotá: Universidad Nacional de Colombia.

Sánchez, E. (2006). Entre el juez Salomón y el Dios Sira. Decisiones interculturales e interés superior del niño. Bogotá: Universiteit Van Ámsterdam, Faculteit der Rechtsgelerdheid.

Santiago, A. (2008). Neoconstitucionalismo. Recuperado de http://ancmyp.org.ar/user/ files/02neoconstitucionalismo.pdf

Semper, F. (2011). Los derechos de los pueblos indígenas de Colombia en la jurisprudencia de la Corte Constitucional. México: Universidad Nacional Autónoma de México, Instituto de Investigaciones Jurídicas. Recuperado de http://www.juridicas.unam.mx/ 
publica/librev/rev/dconstla/cont/20062/pr/ pr3.pdf

Stavenhaguen, R. (2002). Identidad indígena y multiculturalidad en América Latina. Araucaria, 4(7). Universidad de Sevilla. Recuperado de http://redalyc.uaemex.mx/src/inicio/ IndArtRev.jsp?iCveEntRev=282\&iCveNum $\operatorname{Rev}=1583$
Volio, F. (1996). Garantías constitucionales de protección de los derechos indígenas: los casos de Bolivia y Ecuador. Recuperado de:http://www.iidh.ed.cr/comunidades/diversidades/docs/div_docpublicaciones/garantias\%20constitucionales.pdf 